bladder control. After detailed tests of autonomic function multisystem atrophy was diagnosed. She underwent a right saccus endolymphaticus drain age in November 1989, which unfortunately failed to improve her vertigo.

Her symptoms and the results of audiometric and electrophysiological investigations were similar to those found in Menière's disease. The aetiology of Menière's disease is incompletely understood; one long held theory postulates that it is caused by autonomic imbalance with an underlying vasomotor dysfunction leading to arteriolar spasm and atonic capillary dilatation accompanied by alterations in endolymph production. Interestingly, sympathectomy has been widely used to treat Menière's disease.

The Shy-Drager syndrome should therefore be considered as a possible cause of endolymphatic hydrops, especially when associated with other evidence of autonomic dysfunction.

$$
\text { A HINTON }
$$

R T RAMSDEN

S SAEED

D NEARY

P N COOPER

Department of Otolaryngology,

Manchester M13 9W

1 Kew J, Gross M, Chapman P. Shy-Drager syndrome presenting as isolated paralysis of vocal cord abductors. $\mathrm{Br}$ Med $f$ 1990;300:1441. (2 June.)

2 Bannister R, Gibson W, Michaels L, Oppenheimer DR. Laryngeal abductor paralysis in multiple system atrophy. Brain 1981:104:351-68.

3 Gibson WPR, Ramsden RT, Moffat DA. Clinical electrocochleography in the diagnosis and management of Meniere's disorder. Audiology 1977;16:389-401.

4 Godling-Wood PH. Cervical sympathectomy in Meniere' disease. Archives of Otolaryngology 1973;97:391-4

\section{Improving the care of patients with major trauma}

SIR,-Mr R B Fisher and Ms C H Dearden conclude from their study that two simple measures can improve the management of patients with major trauma in the accident and emergency department.' No one would challenge the importance of senior doctors in supervising resuscitation, but their recommendation for the use of the revised trauma score as a triage tool merits further discussion

Readers will assume that the box entitled "Scoring systems used in trauma" is a convenien summary of the revised trauma score and the injury severity score, yet it contains importan inaccuracies. The "coded values" 4 and 3 for respiratory rate have been transposed. More importantly, adding together the coded values for systolic blood pressure, respiratory rate, and Glasgow coma scale does not give the revised trauma score. This is based on regression analysis of a large North American database and is calculated by applying weighting factors to the coded values given in the box. These are Glasgow coma score $\times 0.9368$, blood pressure $\times 0.7326$, and respiratory rate $\times 0 \cdot 2908$, emphasising the relative importance of these three variables to outcome.

The authors acknowledge the importance of accurately recording anatomical injury in order to calculate the precise injury severity score. In their example laceration of the larynx is given an abbreviated injury score of 4 and fracture of the radius a score of 2 . The abbreviated injury score handbook ascribes three scores to laceration of the larynx and two to fracture of the radius depending on the severity of injury. The accepted coding convention is to use the lowest score if more detailed information is not available. The lowest score for a laceration of the larynx is 3 . This would reduce the injury severity score in their example from 26 to 19.

A distinction should be made between the use of injury scoring systems for triage and their use in clinical audit. For triage this can be achieved by using the system advocated by the authors and now employed in other accident and emergency departments, but clinical audit requires more attention to the details of injury descriptors, physiological state, and computation. North American experience would suggest that this can best be achieved by a national coordinating system that provides confidential data analysis based on agreed coding conventions. Additional benefits include the potential for comparative studies between institutions employing different systems of trauma care and the development of a large database, which can be used to refine the scoring systems themselves. All this is now possible in the United Kingdom as a result of the recent decision by the Department of Health to support the development of the major trauma outcome study. ${ }^{2}$ This is based at the North Western Injury Research Centre in Manchester, which would welcome inquiries from interested clinicians.

D W YATES

North Western Injury Research Centre,

Hope Hospital,

Salford $M 68 \mathrm{HD}$

1 Fisher RB, Dearden $\mathrm{CH}$. Improving the care of patients with major trauma in the accident and emergency department. BrMed f 1990;300:1560-3. (16 June.)

2 Anonymous. News and information. Br Med f 1990;300:993. 14 April.)

\section{Traveller mothers and babies}

SIR, - As a clinical medical officer in a mobile child health clinic for travellers, I agree with the points made and the solutions proposed by Drs Gene Feder and Ruth Hussey in their article on traveller mothers and babies.' I believe that traveller children under 5 years represent another group with special needs.

I recently conducted a survey into the immunisation state of traveller children under 5 in Bradford and found generally low rates of uptake of immunisation compared with those in children under 5 in Bradford district as a whole-for instance, only $25-30 \%$ of traveller children had completed their primary diphtheria, tetanus, and polio immunisations (compared with $84 \cdot 5 \%$ of children in the general population), while for pertussis immunisation the rate was even lower $(15 \% v$ $75 \cdot 6 \%$ ).

The factors responsible for poor maternal and perinatal health might also account for this example of poor child health care-for instance, being moved from one inadequate site to another makes completion of immunisations difficult; lack of access to health education might account for the persisting worries about, and hence low take up rate of, pertussis immunisation. In general, travellers' beliefs were not found to be important only one child under 5 had never had any im munisations at all. Thus children under 5 should also be included when considering the needs of travellers.

Bradford BD7 2QB

A B MCKENZIE

1 Feder G, Hussey R. Traveller mothers and babies. Br Med $\mathcal{J}$ 1990;300:1536-7. (16 June.)

\section{Screening for skin cancer}

SIR, - We find the "Screening in Practice" series interesting but are disappointed that no mention has yet been made of the largest and most accessible organ of the body - namely, the skin.

The incidence of all types of skin cancer is increasing in this country and in white people world wide. More importantly, the incidence of melanoma is doubling every $10-15$ years.' In England and Wales mortality from melanoma has more than doubled since $1952 .{ }^{2}$ Between 1974 and 1984 mortality in the age groups $25-34$ years and $35-44$ years increased by $80 \%$ and $64 \%$ respectively. Currently about 1000 people each year die of malignant melanoma (half the number who die of cervical cancer), ${ }^{3}$ but in all probability this figure could be greatly reduced if tumours were detected at an early stage. Certainly in Australia, where awareness of the disease among the general public is high, patients present with much thinner tumours that have a better prognosis..$^{+0}$

During a skin screening survey at the head office of a large retailer we examined 2150 employees and identified four people with melanoma, all with thin lesions that had a good prognosis. An additional six employees were found to have other, less serious, forms of skin cancer. Though we would not advocate that programmes be created specifically for detecting skin cancer in the United Kingdom, we suggest that skin is examined methodically when patients attend for other screening procedures. The opportunity could also be used to increase public awareness about melanoma and ways of protecting the skin from excessive exposure to the sun.

R K CURLEY

Whiston and St Helens Hospitals,

Merseyside

St George's Hospital

R A MARSDEN

London SW $170 \mathrm{QT}$

F G TAYLOR

Marks and Spencer ple

London WIA IDN

1 Muir CS, Nectoux J. Time trends: malignant melanoma of the skin. In: Magnus K, ed. Trends in cancer incidence-causes and practical implications. Washington, DC: Hemisphere, 1982:365-88.

2 Office of Population Censuses and Surveys. Trends in cancer mortality analysed by period of birth and death 1951-1980. London: HMSO 1985. (Series DHI No 11 )

3 Office of Population Censuses and Surveys. Cancer statistics: registrations. England and Wales 1983. London: HMSO, 1986.

4 English DR, Armstrong BK. Identifying people at high risk of cutaneous malignant melanoma: results from a case contro study in Western Australia. Br Med F 1988;296:1285-8.

5 Lemish WM, Heenan PJ, Holman CDJ, Armstrong BK. Survival from preinvasive and invasive malignant melanoma in Western Australia. Cancer 1983;52:580-5.

6 Doherty VR, MacKie RM. Reasons for poor prognosis in British patients with cutaneous malignant melanoma. $\mathrm{Br} \mathrm{Med} \mathcal{f}$ 1986;292:987-9.

\section{Management of menorrhagia}

SIR, - We agree with Dr Adam Magos's commen in his timely editorial that we may be on the threshold of a revolution in the treatment of menorrhagia.' We also agree that before the hysteroscopic alternatives to hysterectomy are widely adopted their safety and efficacy must be determined. Unfortunately the published work on this subject is at present scanty and much less than the enthusiasm surrounding these procedures would seem to imply. The published report of electrodiathermy resection of the endometrium in the treatment of uncomplicated menorrhagia comprised a mere 16 cases, ${ }^{2}$ while the published work on neodymium-yttrium aluminium garnet (Nd-YAG) laser ablation is principally Goldrath's report of 335 cases, which he collected over 10 years. ${ }^{3}$ We would therefore like to add our joint experience of the treatment.

We treated 517 women with menorrhagia by endometrial laser ablation. There were no major intraoperative complications. Two patients developed transient fluid overload with pulmonary oedema; both responded promptly to intravenous diuretics and were discharged within 48 hours. There were also two cases of uterine perforation, both of which occurred during the insertion of the rigid endoscope. In these cases no laser energy was employed, the procedure was discontinued, both patients went home within 24 hours, and on both occasions the treatment was successfully 